\title{
PROTOTIPAGEM RÁPIDA E DESIGN DE PRODUTO ASSISTIVO
}

RAPID PROTOTYPING AND PRODUCT DESIGN ASSISTIVE

Ivan Luiz de Medeiros; Doutorando em Design, PósDesign; UFSC

ivan.medeiros@ufsc.br

Regiane Pupo; Dra; UFSC

Regi.pupo@gmail.com

Alexandre José Müller Kegler; Mestrando PósARQ ;UFSC

mullerkegler@gmail.com

Gilson Braviano; Dr; UFSC

gilson@cce.ufsc.br

Resumo: Esta pesquisa apresenta os principais resultados da aplicação prática da prototipagem rápida, inserida no processo de desenvolvimento de produto assistivo, neste caso voltado especificamente ao público de baixa visão e cegueira, buscando estabelecer novos parâmetros de conforto e acessibilidade. Para estabelecer os requisitos de projeto a observação assistemática juntamente com a análise sincrônica pode contribuir para identificar necessidades relevantes deste público-alvo. Demonstra-se ainda a aplicação de alguns tipos de processos de prototipagem utilizados e inseridos preliminarmente na fase de geração de alternativas, a sua importância antecipando problemas projetuais e validações técnicas facilmente conseguidas com essa ferramenta de projeto de produto.

Palavras-chave: Prototipagem Rápida, Design de Produto, Deficientes Visuais

Abstract: This article presents the results on the practical application of rapid prototyping during assistive product development process, in this case specifically aimed to a blind and visually impaired public. The unsystematic observation and synchronic analysis were important to identify relevant needs of this public and to establish project requirements. The research also shows the application of some kinds of rapid prototyping techniques used during alternative generation phase, besides its importance on anticipating project problems and the technical validation that were easily achieved with these tools.

Key words: Rapid Prototyping; Product Design; Visually impaired. 


\section{INTRODUÇÃO}

É muito comum as pessoas confundirem acessibilidade com aspectos relacionados aos espaços físicos, entretanto, este é um conceito mais amplo que está diretamente ligado à inclusão social. Acessibilidade, segundo a NBR9050 (2004) é a possibilidade e condição de alcance, percepção e entendimento para a utilização com segurança e autonomia de edificações, espaços, mobiliários e equipamento urbano. Neste sentido, Lowenfeld (1948) e Gockman (1969), consideram que a pessoa cega, que não pode locomover-se independentemente, fica limitada em concretizar decisões espontâneas e em assumir ou concluir várias atividades de conhecimento e satisfação pessoal. Afirmam, ainda, que na área social e na interação com o ambiente, a orientação e mobilidade são, sem dúvida, essenciais, pois a dependência da pessoa com deficiência visual nessa área pode levá-la a um estado de isolamento e descrédito.

De acordo com a Organização Mundial da Saúde, atualmente, há 45 milhões de pessoas cegas e 135 milhões de pessoas com baixa visão em todo o mundo. No Brasil, segundo o senso 2010, há mais de 35 milhões de pessoas com deficiência visual. Destes, 506.377 são cegos, 5.056.533 tem grande dificuldade de enxergar e 29.211.482 tem alguma dificuldade de enxergar (Sociedade Brasileira de Oftalmologia ${ }^{1}$ ).

Tendo em vista a necessidade de adequação do produto ao usuário e às suas tarefas, as técnicas de prototipagem rápida utilizadas hoje durante o processo projetual, dispensam os altos custos da produção industrial e facilitam os habituais ajustes que se fazem necessários nas etapas de execução do protótipo. Segundo PUPO (2011), As novas formas de produção associadas à tecnologia digital, hoje, trabalham como grandes aliadas na inovação de projetos, na fabricação e na construção. Os novos meios de produção, nos quais se incluem a prototipagem rápida e a fabricação digital, possibilitam um grau de inovação até então não possível desde a concepção de um projeto de qualquer natureza até sua produção.

Na compreensão deste campo de atuação, este artigo demonstra o processo de projeto de um aparato para pessoas com deficiência visual e baixa visão. A utilização de técnicas de prototipagem rápida durante o desenvolvimento de projeto possibilitou a execução de modelos precisos e fundamentais para decisões de caráter ergonômicos e formais. A finalização do projeto, também com o uso destas tecnologias, tornou possível a execução de um produto que contém sensores para que os usuários possam perceber a proximidade de objetos por meio de vibração e com isso evitar choques físicos com obstáculos diversos. Desta maneira, a prototipagem rápida, aqui entendida como ferramenta no processo projetual, possibilitou agilidade e assertividade no processo de design de produtos assistivos.

\section{REVISÃO DE LITERATURA}

\subsection{A Materializaçao da forma}

A possibilidade de incorporar os novos meios de produção na pesquisa e desenvolvimento de novos produtos traz novas perspectivas de avanço e inovação no aprendizado e assimilação do conhecimento. Hoje, os projetos não são somente criados digitalmente, mas também produzidos digitalmente, seja pela prototipagem

\footnotetext{
${ }^{1}$ www.sboportal.org.br
} 
rápida ou por processos de fabricação digital, numericamente controlados por computador (CNC), comumente chamados de processos "file-to-factory" (PUPO, 2011). A tradução literal do processo "file-to-factory" como sendo "do arquivo para a fábrica", se caracteriza quando o modelo digital 3D se comunica diretamente com as máquinas de corte programáveis. Segundo Osterhuis (2005), o processo file-to-factory se refere a uma mesclagem entre o processo de projeto e a fabricação, envolvendo a transferência direta de dados (código G) a partir de um software 3D para uma máquina. Em todos os casos, novas estratégias de projeto são empregadas e baseadas em conceitos computacionais. Com isso, as técnicas de fabricação digital e a escolha de materiais, do ponto de vista do projeto, passam a ter um papel importante durante o processo de projeto e na estética do produto final. Pottmann et al (2008, p. 572) explicam que "a escolha da técnica de fabricação pode levar à uma estética particular devido à interpretação da geometria, necessária para produzir as partes. Essa interpretação pode ter grande influência no desenvolvimento do projeto". A expressão "digital materialization" (materialização digital) ou "digital materiality" (materialidade digital), por exemplo, é aqui proposta como um termo geral para designar todas as tecnologias de produção disponíveis para a produção de artefatos físicos.

\subsection{Prototipagem Rápida}

Segundo (BUSWELL, R., et al., 2007) o termo prototipagem rápida (PR) referese, normalmente, aos métodos de produção de protótipos por sistemas aditivos. Ou seja, o processo de fabricação é feito por meio de adição de material, camada por camada, permitindo a produção de protótipos ou modelos em três dimensões a partir de modelos geométricos gerados em sistemas CAD (Computer-Aided-Design).

Para PUPO (2009) a Prototipagem Rápida é uma ferramenta poderosa para reduzir o tempo de produção enquanto aumenta a qualidade e reduz custos, entretanto, enquanto algumas teorias revelam a PR como sendo unicamente os processos que se utilizam da sobreposição de camadas de qualquer material visando a formação de um protótipo físico, outras não estabelecem parâmetros e a definem pelos métodos que exclusivamente utilizam equipamentos automatizados.

A técnica de execução de protótipo rápida é usada para criar rapidamente modelos e protótipos. No entanto, o mesmo processo de desenho e modelagem em CAD pode ser utilizado para fazer cortes e moldes necessários a fim de produzir produtos finais manufaturados. O modelo criado em protótipo rápido pode ser produzido nos materiais especificados para o design final, da mesma maneira, que os produtos finais podem ser produzidos usando técnica de prototipagem rápida (MORRIS, 2010). Segundo Duarte (2007), “... os processos de fabricação e montagem têm de ser organizados de modo a que minimizem o custo do recurso à construção não repetitiva". Completa que "... O uso progressivo de dispositivos de fabricação e montagem programáveis, combinados com a modularidade de componentes e de submontagens e com a padronização das suas ligações, pode manter tal custo dentro de limites aceitáveis."

\subsubsection{Processos Aditivos}

As técnicas de prototipagem rápida aditiva baseiam-se em um processo de construção tridimensional que se dá por meio da adição de material em forma de 
camadas planas sucessivas (VOLPATO et al., 2007). Pode ser mais detalhado como "Um pacote de software que "fatia" o modelo do componente em CAD em várias camadas finas, com aproximadamente $0,1 \mathrm{~mm}$ de espessura, as quais são dispostas uma sobre a outra" (Gorni, 2001, p.2).

Uma das principais técnicas do processo aditivo é a Sinterizaçao Seletiva a Laser (SLS), que utiliza um laser CO2 para queimar, ou sinterizar, um material (pó), camada por camada, até que o modelo esteja totalmente construído. Seu mecanismo muito se assemelha à estereolitografia (SLA), mas ao invés de resina líquida, são utilizadas resinas em pó. Uma fonte de laser transforma o pó em sólido por um processo de aquecimento instantâneo que permite que as superfícies de partículas se fundam numa operação de "sinterização" (Shodek, 2005, p. 291). O processo SLS utiliza um cilindro sobre uma plataforma para inicialmente nivelar e espalhar o pó. Na continuação, um feixe de laser, deslocado por um sistema de varredura, é então direcionado à superfície onde está o pó espalhado, cujas partículas são sinterizadas de acordo com a geometria da camada $2 \mathrm{D}$ da peça. A plataforma que suporta a peça se desloca no eixo Z, para baixo, exatamente na distancia igual à espessura da camada e uma nova camada de material é espalhada na plataforma, sobre a anterior. O processo é repetido até que todas as camadas sejam depositadas e a peça esteja totalmente completa. O material que não é fundido suporta as partes solidificadas, permitindo a construção de peças em balanço ou com furos, sem a necessidade de suportes, removido ao final do processo.

A tecnologia mais comum hoje em dia é a chamada Modelagem por Fusão e Deposição (Fused Deposition Modeling - FDM), que utiliza material plástico ABS e policarbonatos em forma de filamento. Devido ao número de pesquisas investidas neste tipo de tecnologia, é possível encontrar, hoje, impressoras com preços acessíveis, em tamanhos equivalentes aos formatos desktop. O processo de impressão é bem simples e consiste no tracionamento do filamento plástico para um cabeçote com um bico extrusor, derretido e expelido, também em filamentos, criando camada por camada (com o equivalente a $0.127 \mathrm{~mm}$, dependendo do bico), até completar o modelo. $O$ cabeçote de extrusão aquecido movimenta-se nos eixos $X$ e $Y$, enquanto a base, onde a peça será construída, movimenta-se no eixo Z. À medida que o filamento de material, já derretido, chega à extremidade do bico extrusor, vai sendo depositado e solidificado, aderindo-se à camada anterior. A distância de movimento no eixo $Z$ vai depender dos ajustes pré-estabelecidos no software utilizado para a preparação do arquivo. Seus modelos têm boa durabilidade, com a possibilidade de processamento em cera ou plásticos coloridos.

\section{ATIVIDADE PROJETUAL}

\subsection{Metodologia de Projeto de Produto}

O processo de desenvolvimento de produto tem se mostrado cada vez mais estratégico e importante para as empresas. Para Rozenfeld, et al. (2006) uma característica organizacional específica do processo de desenvolvimento é que cada projeto pode apresentar problemas, dificuldades e históricos específicos e particulares, ou seja, a atividade de desenvolvimento não é uma atividade rotineira, como ocorre nos processos financeiros ou de produção. $O$ autor ainda salienta que as escolhas de alternativas ocorridas no início do ciclo de desenvolvimento são responsáveis por cerca 
de $85 \%$ do custo do produto final. Assim, todas as outras definições e decisões a serem tomadas ao longo do ciclo de desenvolvimento, após as fases iniciais, determinam os restantes $15 \%$ do custo (Figura 1 ).

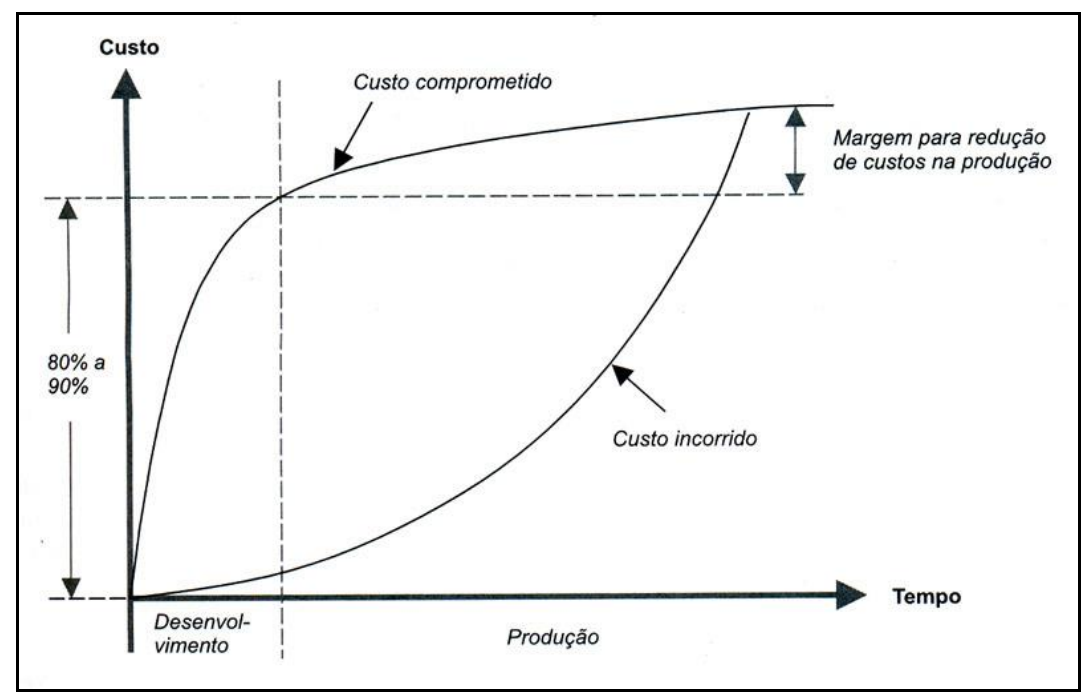

Figura 1 - Curva de comprometimento do custo do produto

Fonte: Rozenfeld et al. (2006)

Segundo Freixo e Toledo (2003), promover modificações quando o produto não passa de um conceito, de uma ideia, é menos trabalhoso e envolve menos recursos que realizar alterações quando os projetos e processos já tenham sido definidos. Para Rozenfeld, et al. (2006) com o tempo decorrido no processo de desenvolvimento de produto, as incertezas vão diminuindo de acordo com as definições que vão sendo adotadas. Mas o fato concreto é que é preciso tomar decisões importantes quando ainda se têm muitas incertezas.

Com a ampliação das oportunidades de acesso à tecnologia de impressão 3D, por exemplo, a prototipagem rápida tem auxiliado neste processo de tomada de decisão e validação de alternativas cada vez mais cedo no processo de desenvolvimento de produto. Sendo assim, foi fundamental e relevante uma compreensão do maior número possível de possibilidades neste campo de tecnologia aplicada para que o processo fosse compreendido e aplicado apropriadamente em cada fase do projeto.

\subsection{Análise Sincrônica}

Existem no mercado projetos que visam proteger a integridade física de pessoas com deficiência visual e permitir uma maior mobilidade e autonomia. Entretanto, não são tarefas fáceis, pois dependem de inúmeras variáveis que nem sempre estão sob controle dos projetistas, tais como construções irregulares, sistemas de sinalização que não funcionam ou são mal projetados, dentre outros inúmeros obstáculos que esta população têm de enfrentar no dia a dia. Para exemplificar as atuais soluções, uma rápida análise sincrônica foi estruturada (Figura 2) direcionada a estes produtos existentes e em desenvolvimento no mercado. Para essa análise foram selecionados produtos que procuravam dar maior liberdade para as mãos dos deficientes visuais. 


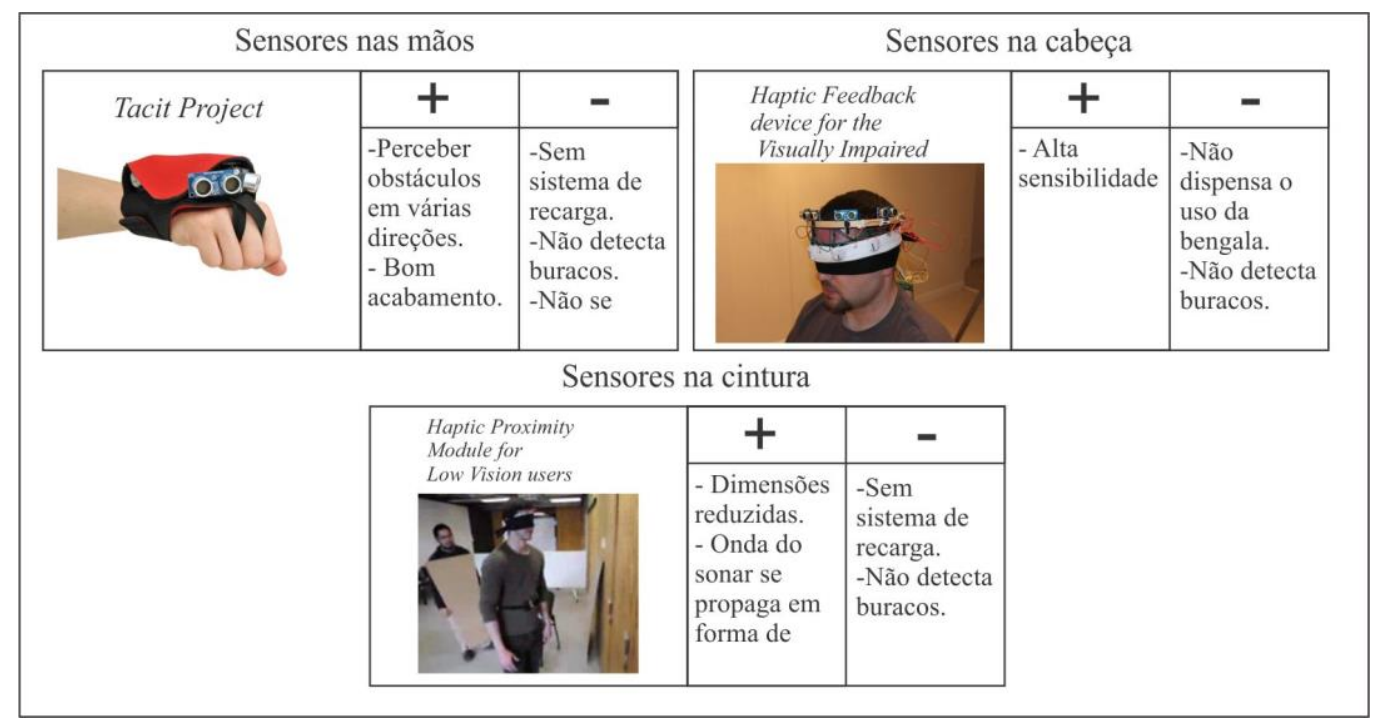

Figura 2 - Análise Sincrônica

Fonte: Elaborado pelo autor, com base na pesquisa realizada

A análise sincrônica foi fundamental para identificar características essenciais para a execução do projeto, tais como: 1) Necessidade de proteger todas as partes do corpo de um possível choque com objetos; 2) Necessidade de um sistema de recarga das baterias em alguns projetos; 3) Facilidade de manipulação; 4) Adaptabilidade às características físicas do usuário; 5) Capacidade de perceber obstáculos em várias direções; 6) Ter dimensões reduzidas;

Dentre as características citadas, a que mais se destacou foi a impossibilidade destes equipamentos detectarem buracos e desníveis no percurso, característica esta que transforma estes equipamentos em acessórios de auxílio à bengala.

\section{3. $\mathrm{ACIC}$}

A ACIC (Associação Catarinense para Integração dos Cegos) foi fundada em 18 de junho de 1977 por um grupo de pessoas cegas e hoje é considerada como uma Organização não Governamental, sem fins lucrativos e de caráter sócio assistencial. Atende à pessoas cegas ou com baixa visão de todo o estado de Santa Catarina por meio de prestação de serviços nas áreas de habilitação, reabilitação, saúde, cultura, educação, profissionalização, esporte, estudos, pesquisa e desenvolvimento pleno da cidadania. Foi nesta associação que a primeira parte da pesquisa se fundamentou, com a aplicação de questionários e práticas de observação com alunos e usuários locais.

\subsection{Observação Assistemática}

As observações foram fundamentais para conhecer melhor as dificuldades das pessoas com deficiência visual e serviu de laboratório para a problemática levantada nas pesquisas teóricas. Esta técnica foi aplicada acompanhando algumas pessoas com deficiência visual dentro do ambiente da ACIC. Em diferentes momentos, a observação se deu em situações do cotidiano, tais como na entrada na instituição, no deslocamento até as salas de aula, em algumas aulas do curso de orientação e mobilidade, em horários de intervalo e na saída da instituição. Cada um destes 
momentos apresentou algum tipo de particularidade importante para o desenvolvimento do projeto em questão. Na chegada à instituição, muitos dos alunos apresentaram dificuldades ao se deslocar pelo ambiente tumultuado que se forma no portão de entrada. Entretanto, os alunos que já haviam frequentado aulas de orientação e mobilidade se deslocavam com maior cautela e dificilmente esbarravam em outras pessoas. Os usuários com mais idade e treino reconheciam outras pessoas pela voz e pelo estalar da bengala ao bater no chão. Vários deles se cumprimentavam e perguntavam de que local estavam vindo e para onde estavam indo, também como técnica de orientação. É comum, em situações em que há uma rotina das pessoas que frequentam a instituição, saber a direção que as pessoas vêm e vão e assim formar um mapa mental que auxilia no deslocamento.

O deslocamento até as salas de aula é auxiliado por recursos sonoros e táteis, em todos os corredores da instituição. Há caixas de som tocando músicas constantemente servindo como guia para os usuários. No chão, em todos os corredores, são instalados pisos de sinalização tátil que servem para orientar os alunos auxiliando a função da bengala. Entretanto, mesmo com esses recursos, casos específicos de cegueira por diabetes podem reduzir sensivelmente a audição e diminuir a sensibilidade nas extremidades como mãos e pés.

As aulas oferecidas na instituição incluem leitura braile, orientação e mobilidade, técnicas de informática e manutenção de computadores. Todas mostraram alguma particularidade sobre as práticas do dia a dia, mas a que mais se destacou foi a de orientação e mobilidade. Nela, os alunos aprendem a se deslocar em ambientes diversos e a utilizar técnicas para a proteção de sua integridade física. Os alunos aprendem a manusear a bengala para se deslocar e desviar de obstáculos e também a acompanhar sons do ambiente (carros passando, pessoas conversando). Outros sentidos, como o tato ao perceber os pisos direcionais e buracos, o vento tocando a pele, a percepção de cheiros e sinais de alerta de uma forma geral, auxiliam no reconhecimento de um ambiente qualquer para a formação do mapa mental do ambiente em questão.

O momento da saída dos alunos é muito similar com o da entrada; utilizam os mesmos meios para se deslocar, mas com muita atenção ao atravessar a rua. Escutam atentamente os sons de carros e pedestres e não hesitam em pedir ajuda à pessoas que enxergam. Os próprios alunos são orientados a ensinar a forma correta de conduzir uma pessoa com deficiência visual, que é deixar o próprio segurar ou se apoiar na pessoa que o conduz.

\subsection{Questionários}

Participaram da pesquisa um total de 23 pessoas ( 13 do sexo masculino e 10 do sexo feminino) entre os dias 16 de junho e 10 de agosto de 2013, sendo que desse total, cinco pessoas se declararam com baixa visão e 18 pessoas se declararam cegas.

Os usuários puderam responder livremente quais os principais recursos utilizados por eles para se locomover. Observou-se que poucas pessoas utilizam o cão guia devido ao cuidado necessário com o animal e o alto custo para aquisição e treinamento do mesmo. Dos 23 participantes, 20 já haviam frequentado aulas de orientação e 
mobilidade e as principais contribuições percebidas foram mais evidenciadas no campo emocional do que necessariamente no físico. Quando questionados sobre qual o sentido mais apurado, $61 \%$ dos participantes responderam que ambos os sentidos (audição e tato) são igualmente desenvolvidos; $26 \%$ afirmaram que a audição é mais apurada e $13 \%$ confirmaram que o tato é mais apurado.

Os participantes puderam citar livremente suas principais dificuldades na locomoção e os resultados foram separados em duas categorias: os obstáculos altos e os obstáculos baixos. Apesar dos itens internos às categorias serem semelhantes, optou-se por mantê-los da forma que foram descritos pelos participantes. Todos os participantes citaram alguma dificuldade com obstáculos baixos e $80 \%$ citaram alguma dificuldade com obstáculos aéreos.

A partir da problemática descoberta precisava-se conhecer a solução mais adequada que levasse em consideração as informações vindas do usuário. Neste momento, procurou-se entender qual o local mais adequado para o posicionamento do equipamento a ser projetado. Do total, $92 \%$ dos usuários escolheram o ponto médio do corpo, mãos e cintura, talvez por ser o local em que a bengala é segura e vários dos que escolheram a cintura alegaram que um equipamento como este deve deixar as mãos livres para que se possa carregar outros objetos.

\subsection{Requisitos de Projeto}

Com base na pesquisa bibliográfica, observações, questionários e ferramentas projetuais foi possível estabelecer uma lista de requisitos necessários a serem respeitados para a concepção formal do produto, respeitando as características dos usuários e seus anseios. Juntamente com as limitações técnicas dos componentes eletrônicos selecionados condizentes com o problema pré-estabelecido, os requisitos são apresentados na Tabela 1.

\begin{tabular}{|c|l|}
\hline Obrigatório & Requisitos de projeto \\
\hline $\mathbf{x}$ & Ajustável na cintura \\
\hline $\mathbf{x}$ & $\begin{array}{l}\text { Respeitar } \\
\text { antropométricas }\end{array}$ \\
\hline $\mathbf{x}$ & Fácil acesso aos controlesísticas \\
\hline $\mathbf{x}$ & Não limitar os movimentos \\
\hline $\mathbf{x}$ & Sem cantos vivos \\
\hline $\mathbf{x}$ & Fácil instalação e manipulação \\
\hline $\mathbf{x}$ & Utilizar escrita Braile nas informações \\
\hline $\mathbf{x}$ & Utilizar o sentido tátil (vibração) \\
\hline $\mathbf{x}$ & Feedback sonoro \\
\hline $\mathbf{x}$ & Recarregar as baterias \\
\hline $\mathbf{x}$ & Botão liga e desliga \\
\hline
\end{tabular}

Tabela 1 - Requisitos de Projeto

Fonte: Elaborado pelo autor, com base na pesquisa realizada

\subsection{Geração de alternativas com materialização}

Com a definição dos requisitos de projetos, juntamente com as análises realizadas, pôde-se dar início a geração de alternativas. Nesta etapa buscou-se um processo dinâmico de desenvolvimento com a aplicação da prototipagem. Inicialmente desenvolvendo alternativas com sketches manuais e posteriormente modelando 
tridimensionalmente em software, algumas alternativas foram diretamente modeladas e prototipadas. Para melhor compreensão desta etapa do projeto a figura 3 apresenta o processo criativo mesclado com a prototipagem. As alternativas seguiram basicamente dois caminhos, pulseiras e cintos.

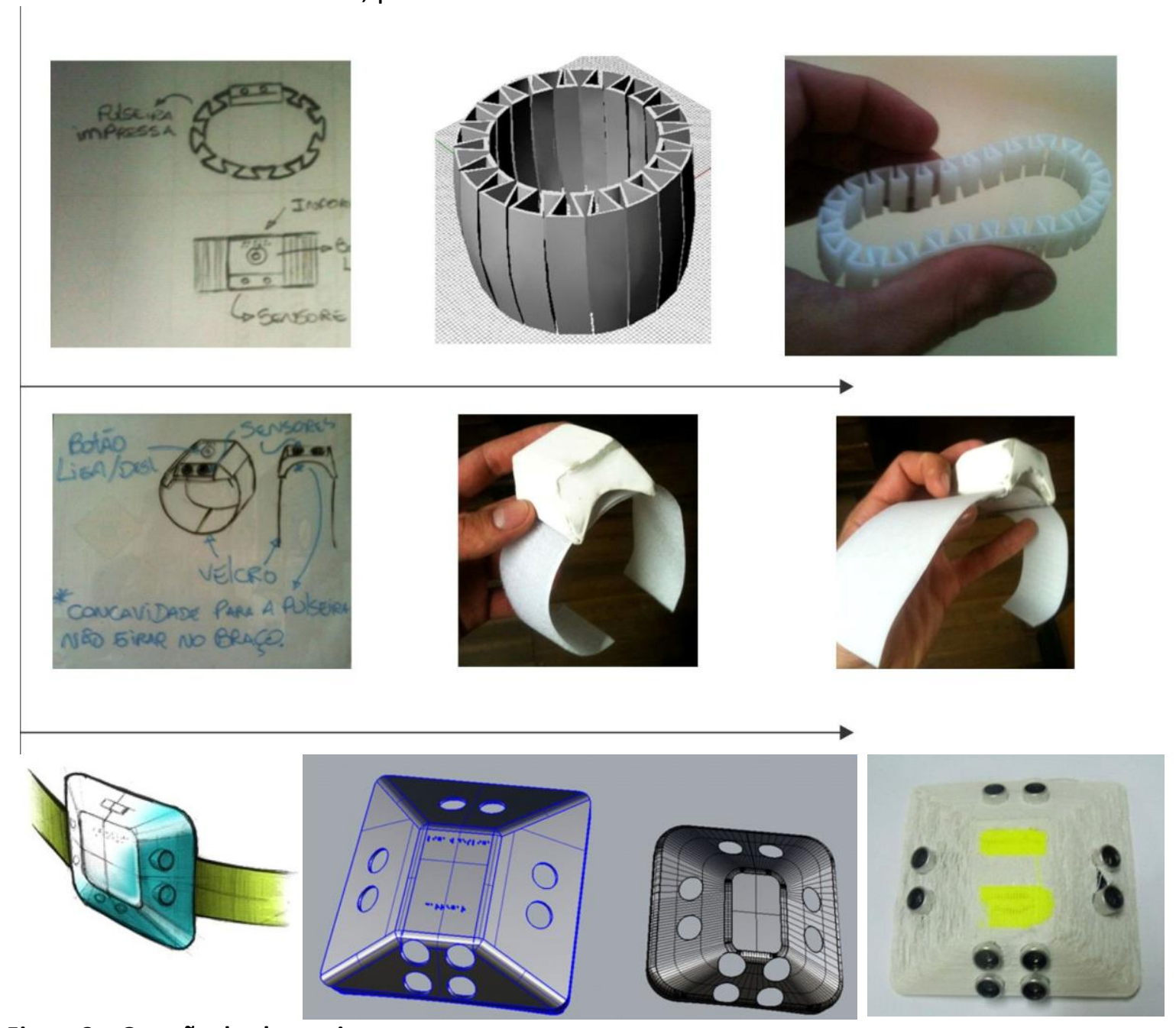

Figura 3 - Geração de alternativas

Fonte: Elaborado pelo autor, com base na pesquisa realizada

O uso da materialização durante o processo de projeto foi efetivado em duas fases. Na primeira, durante os estágios iniciais, por uma impressora de tecnologia FDM, modelo BFB 3D Touch, da marca Stratasys. Utilizando filamento de plástico ABS, os modelos gerados desde as primeiras ideias de geração de alternativas serviram como fatores decisórios quanto a itens como proporções, dimensões, estética, ajuste dos componentes internos e adequação à ergonomia (Figura 4). 

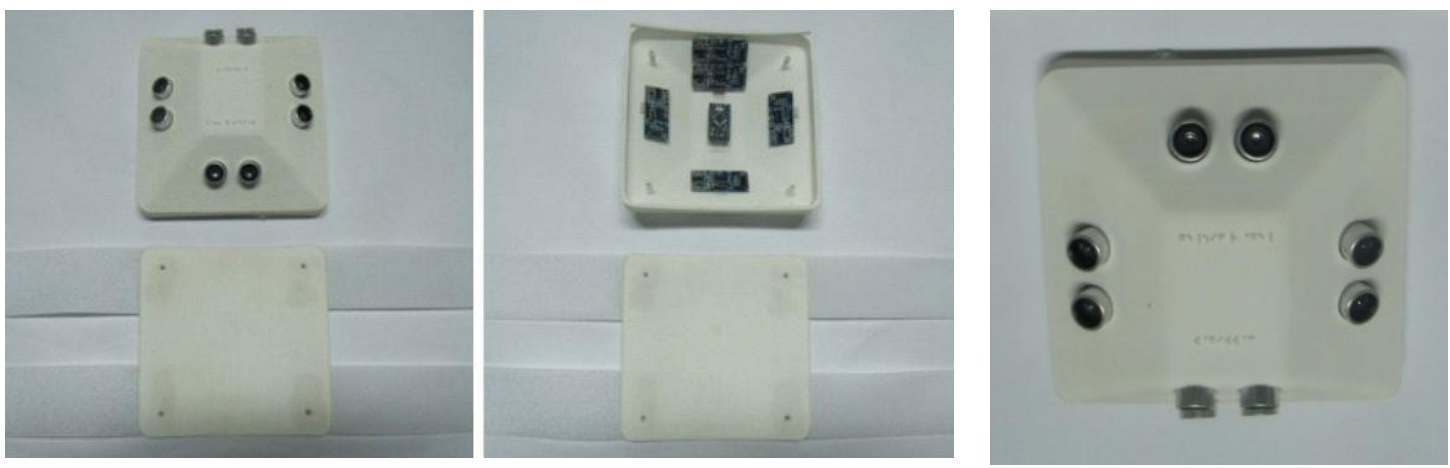

Figura 4- Protótipos impressos em FDM

Fonte: Elaborado pelo autor, com base na pesquisa realizada

Na segunda fase foi utilizada uma impressora de resina líquida sinterizada por luz, a Projet1000, fabricada pela 3D Systems, que reuni características de maior precisão e qualidade frente às impressoras de filamento. A análise física deste último protótipo, na alternativa final, apresentada na figura 5, proporcionou maior compreensão de diversos componentes de projeto, optando-se pela redução de tamanho do modelo (de $150 \times 150 \times 40 \mathrm{~mm}$ para $120 \times 120 \times 43 \mathrm{~mm}$ ). Consequentemente, os elementos frontais foram reposicionados devido à redução das dimensões. Os raios dos cantos foram aumentados e as quinas frontais foram eliminadas. As torres da cela braile foram ajustadas às normas e tiveram as pontas arredondadas. Para dar suporte e melhorar a aparência da parte visível dos sensores foram inseridas bordas ao redor, na parte externa do protótipo e no seu interior foram inseridos suportes e travas para os componentes. Ainda, foi criado um espaço para o botão liga/desliga e para o buzzer (alerta sonoro). Além disso, nesta etapa, foi possível perceber e especificar mais precisamente as cavidades internas do produto que seriam utilizadas para 0 posicionamento dos componentes eletrônicos. Vale lembrar aqui que sem a análise do protótipo físico, a identificação dos problemas citados poderiam não ser tão evidentes se analisadas de forma virtual.
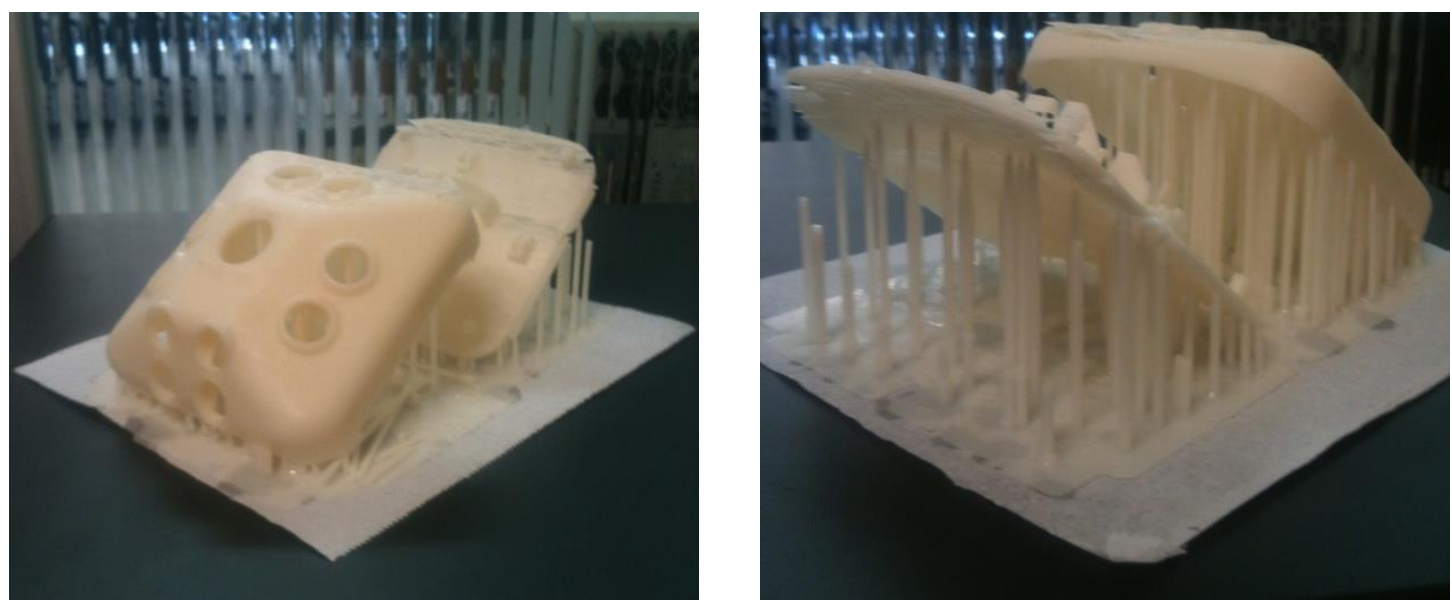

Figura 5- Protótipos impressos em resina líquida Fonte: Elaborado pelo autor, com base na pesquisa realizada 
Após todas as alterações acima descritas, foi definida a alternativa que melhor comportava os componentes eletrônicos internos e externos, a estética e que pudesse ser ergonomicamente viável aos usuários, além de todas as variáveis do projeto. 0 último protótipo então foi realizado, com a técnica aditiva SLS (Selective Laser Sintering), com qualidade de impressão superior às versões anteriores e já incluídas as torres para fixação dos parafusos e o encaixe para a tampa traseira (Figura 6). Esta impressão foi realizada no CTI - Centro de Tecnologia da Informação Renato Archer, em Campinas, São Paulo. Este protótipo possibilitou testes de usabilidade no seu real contexto de uso com usuários e voluntários, validando a proposta inicial.
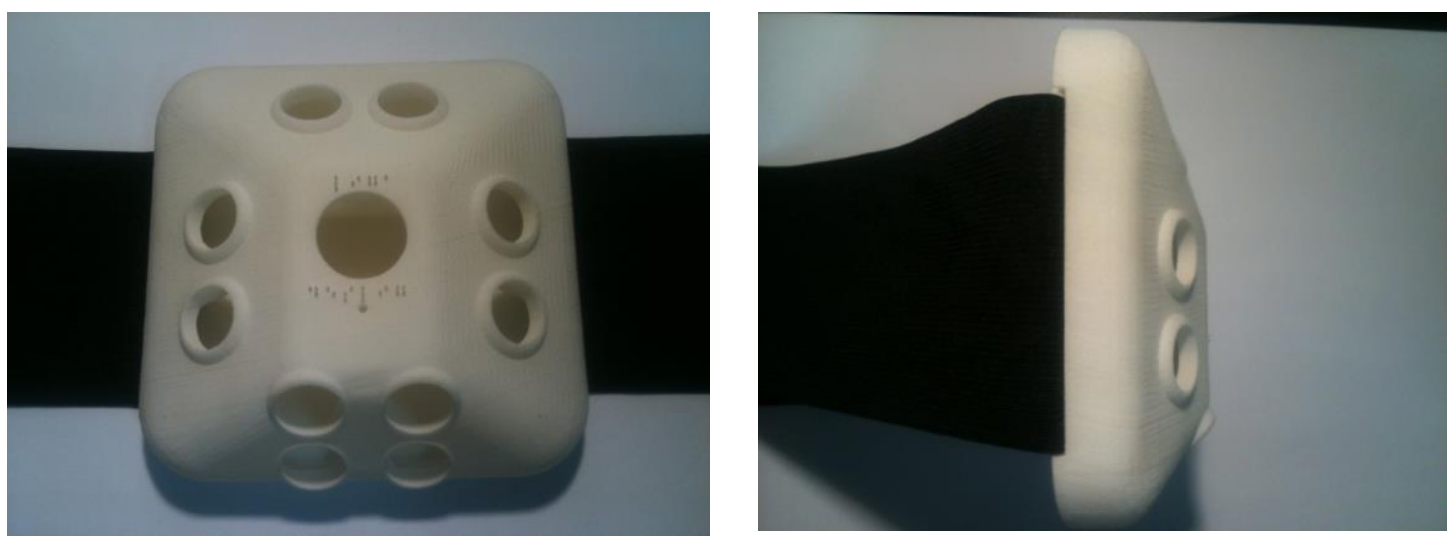

Figura 6- Protótipos finais em SLS

Fonte: Elaborado pelo autor, com base na pesquisa realizada

\section{CONCLUSÃO}

Pode-se concluir que o desenvolvimento do projeto atingiu o objetivo de criar um produto capaz de proteger o deficiente visual de obstáculos. Entretanto não substitui a bengala, há muito tempo a principal e mais efetiva ferramenta de auxilio às pessoas com deficiência visual. A prototipagem rápida foi fundamental para o desenvolvimento, validação e execução do projeto, demonstrando de uma forma prática as falhas de projeto e processo, permitindo assim melhorar continuamente todas as etapas.

Este presente trabalho demonstra uma pequena oportunidade de designers olharem com mais cuidado para públicos tão específicos e carentes de produtos mais adequados ao seu cotidiano. Vale também ressaltar as inúmeras possibilidades neste campo de pesquisa tanto a aplicação da prototipagem rápida quanto o desenvolvimento de produtos assistivos.

\section{AGRADECIMENTOS}

Os autores agradecem o Centro de Tecnologia da Informação Renato Archer pela colaboração durante o processo de projeto com a impressão final do protótipo em tecnologia SLS, não disponível na universidade onde a pesquisa se desenvolveu.

\section{REFERÊNCIAS}

BUSWELL, R.; SOAR R.; GIBB, A.; THORPE, A. Freeform Construction: Mega-scale Rapid Manufacturing for construction. In: Automation in Construction 16, 2007, p.224-231. 
DUARTE, J. Personalização de Habitação em Série: Um Gramática Discursiva para as Casas da Malagueira do Siza. Fundação Calouste Gulbenkian: Lisboa, 2007. Prefácio de Siza Vieira e William Mitchell.

FREIXO, Osvaldo M., TOLEDO, José C. de. Gestão dos Custos do Ciclo de Vida do Produto durante seu Processo de Desenvolvimento. IV Congr. Bras. Gestão e Desenv. de Produtos - Gramado, RS, Brasil, 6 a 8 de out de 2003.

GOCKMAN, R. L. Orientation and Mobility Skills for Children. [S.I.]: [s.n.], 1969.

<http://www.jusbrasil.com.br/legislacao/982145/lei-7801-08-florianopolis-0>.

GORNI, A. A. Introdução à Prototipagem Rápida e seus Processos. Plástico Industrial, SãoPaulo, n 31, 2001.

LOWENFELD, B. Effects of Blindness on Cognitive Functions of Children. [S.I.]: [s.n.], 1948.

MORRIS, R. Fundamentos do design de produto - Porto Alegre. Bookman, 2010.

OSTERHUIS, K. File to Factory and Real Time Behavior in ONLArchitecture. 2005. Disponível em: Http://www.oosterhuis.nl/quickstart/index.php?id=457

POTTMANN, H. E. A. Architectural Geometry. Londres: [s.n.], 2007.

PUPO, R. T. Ensino da prototipagem rápida e fabricação digital para arquitetura e construção no Brasil: definições e estado da arte. PARC, v. 1, p. 1-19, 2008.

PUPO, R. T. A Prototipagem Rápida e a Fabricação Digital: um novo desafio para o ensino de arquitetura. Campinas: [s.n.], 2011.

ROZENFELD, Henrique et al. Gestão de desenvolvimento de produtos: uma referência para a melhoria do processo. São Paulo: Saraiva, 2006.

SCHODEK, D. et al. Digital Design and Manufacturing. New Jersey: John Wiley and sons, 2005.

VOLPATO, N., et al.,Prototipagem Rápida - Tecnologia s e Aplicações . Edgar Blucher, São Paulo, 2007. 